\title{
Identifying ways of closing the metal flow loop in the global mobile phone product system: A system dynamics modeling approach
}

\author{
Rajib Sinha*, Rafael Laurenti, Jagdeep Singh, Maria E. Malmström, Björn Frostell \\ Industrial Ecology, Department of Sustainable Development, Environmental Science and Engineering (SEED), KTH Royal Institute of Technology, Stockholm,
} Sweden

\section{A R T I C L E I N F O}

Article history:

Received 25 January 2016

Received in revised form 19 May 2016

Accepted 22 May 2016

\section{Keywords:}

Closed loop

Eco-cycle

Mobile phones

System dynamics

Substance flow analysis

E-waste

End-of-life

\begin{abstract}
A B S T R A C T
In the past few decades, e-waste has emerged as one of the fastest growing and increasingly complex waste flows world-wide. Within e-waste, the life cycle of the mobile phone product system is particularly important because of: (1) the increasing quantities of mobile phones in this waste flow; and (2) the sustainability challenges associated with the emerging economies of reuse, refurbishment, and export of used mobile phones. This study examined the possibilities of closing the material flow loop in the global mobile phone product system (GMPPS) while addressing the broad sustainability challenges linked to recovery of materials. This was done using an adapted system dynamics modeling approach to investigate the dominant paths and drivers for closing the metal flow loop through the concept of eco-cycle. Two indicators were chosen to define the closed loop system: loop leakage and loop efficiency. Sensitivity analysis of selected parameters was used to identify potential drivers for closing the metal flow loop. The modeling work indicated leverage for management strategies aimed at closing the loop in: (i) collection systems for used phones, (ii) mobile phone use time, and (ii) informal recycling in developing countries. By analyzing the dominant parameters, an eco-cycle scenario that could promote a closed loop system by decreasing pressures on virgin materials was formulated. Improved policy support and product service systems could synchronize growth between upstream producers and end-of-life organizations and help achieve circular production and consumption in the GMPPS.
\end{abstract}

(c) 2016 Elsevier B.V. All rights reserved.

\section{Introduction}

Waste electrical and electronic equipment (WEEE, also well known as e-waste) is one of the fastest growing waste flows worldwide (Kuehr, 2012). On a global scale, e-waste increased from 20 million tons in 1998 to 41 million tons in 2010 and was estimated to reach 50 million tons by 2014/2015 (Kuehr, 2012). The European Commission has estimated that the average European citizen generates $17-20 \mathrm{~kg}$ e-waste per year, and that mobile phones are a potential candidate for generating e-waste (Basel-Convention, 2008). Indeed, mobile phone subscribers have increased exponentially during the past 20 years (Basel-Convention, 2008; ITU, 2013), resulting in more e-waste at the end-of-life (EoL) (PanambunanFerse and Breiter, 2013). In industrialized countries (IC), less than

\footnotetext{
* Corresponding author at: Division of Industrial Ecology, Department of Sustainable Development, Environmental Science and Engineering (SEED), KTH Royal Institute of Technology, Teknikringen 34, 10044 Stockholm, Sweden. Tel.: +4687906744.

E-mail address: rajib.sinha@abe.kth.se (R. Sinha).

URL: http://www.kth.se (R. Sinha).
}

$20 \%$ of used phones are properly managed at EoL (PanambunanFerse and Breiter, 2013; Umair et al., 2013).

With rapid technological improvements and innovations, users frequently replace their phones, decreasing the life span (BaselConvention, 2008; Kuehr, 2012; Tischner, 2012; Herat and Agamuthu, 2012). Because of the potentially remaining active life in used phones and the possibility to upgrade mobile phones at a lower price, interest in using second-hand (or/and refurbished) phones has emerged in both IC and developing countries (DC). In addition, due to increasing interest in e-wastes for reuse and informal recycling in DC, IC export e-wastes to DC (Umair et al., 2013). In DC, these wastes mostly end up in landfills after informal recycling consisting of manual dismantling with bare hands and open burning (Panambunan-Ferse and Breiter, 2013; Umair et al., 2013). Due to a very low overall recovery rate in this informal recycling (Bollinger et al., 2012; Herat and Agamuthu, 2012; Umair et al., 2013), the global mobile phone product system (GMPPS) loses a substantial amount of valuable resources that could be recovered (Basel-Convention, 2008; Geyer and Blass, 2010; Tischner, 2012; Wang et al., 2013).

In a life cycle perspective, the EoL management of mobile phones is a global, rather than a local or regional, problem and 
involves a multitude of actors such as consumers, manufacturers, retailers, collectors, refurbishers, recyclers. In addition, emerging socio-technical/economic activities among these actors (e.g., reuse, export of e-waste, informal recycling) make the EoL complex. For example, export of used phones to DC increases their life span, but valuable metals (used in phones) are lost through informal recycling in DC, whereas IC have better and more efficient technologies for recycling. Apart from reuse or export, consumers either hibernate phones by storing them unused in drawers, or throw away/dump their phones, due to lack of proper collection systems. This study investigated the factors and activities that are the drivers for closing the material flow loop in the GMPPS. To investigate the drivers in such a complex global system and to produce insights into closing the material flow loops efficiently, a broader systems approach with dynamic analysis is warranted to understand the system (Sterman, 2000).

System dynamics (SD) approach, which is grounded on feedback control theory and non-linear dynamics (Sterman, 2000), can be used to explain the behavior of complex systems to better understand GMPPS. Studying various interconnections in the GMPPS using this approach could help explore the complexity of alternative EoL systems and assist in decision making and in development of effective interventions in complex systems. Apart from the SD approach, agent-based modeling (ABM) can be used to explore complexity (Sterman, 2000; Bollinger et al., 2012; Achachlouei, 2015). Bollinger et al. (2012) compared SD and ABM approaches for modeling metal flows in a mobile phone product system and concluded that the SD approach is beneficial for aggregated analysis, whereas ABM has advantages for individual action analysis. The present study deals with the global system and aggregated flows and parameters, and therefore SD modeling was selected as the analytical approach to create a deeper understanding of the GMPPS in a life cycle perspective and to explore an eco-cycle scenario (see Section 2).

In similar research, Spengler and Schröter (2003), Georgiadis and Besiou $(2008,2010)$ studied electrical and electronic products using SD to investigate closed-loop material flows. However, their studies mainly focused on supply chain management and the influence of consumer behavior, while effects of other factors, e.g., using a product for a longer time, on a closed-loop system received little scrutiny. Asif et al. (2015) used SD models to analyze the potential application of product multiple life cycles (Asif, 2011; Asif et al., 2012) in a closed-loop supply chain based on the dynamics of material scarcity. The present study extended the investigation on causal loop diagram (CLD) studies, often used during the initial stages of SD modeling (Sterman, 2000). Nguyen et al. (2015) used CLD to understand smartphone usage in Singapore by exploring the leverage points and resistance to change. Our research group also has previously used CLD to analyze unintended environmental consequences when designing electronic products, using an example of closing the material flow loop in the mobile phone product system (Laurenti et al., 2015a,b,c). The present study also extended the analysis in other types of dynamic modeling studies performed on e-wastes and on mobile phones. Most of the studies conducted dynamic analysis on small-scale systems (Williams et al., 2013), for example e-waste management in a city or a country level, without considering a life cycle perspective (Andarani and Goto, 2013). To our knowledge, a broader systems approach, i.e., with a life cycle perspective and dynamic analysis, has previously only been applied to the mobile phone product system by Bollinger et al. (2012).

In a broader systems approach, Bollinger et al. (2012) performed a dynamic substance flow analysis of global flows of metals in mobile phones in a cradle-to-cradle perspective. The study was based on the research question "... [w] hat [modeling] conditions foster the development of a closed-loop flow network for metals in mobile phones?". The focus was on comparing SD and ABM approaches, while testing and implementing the modeling outcomes in the real world were beyond the scope of the study. However, the model has potential applications in a real-world situation. Adopting the SD model of Bollinger et al. (2012), the aim of the present study was to investigate possibilities to close the metal flow loop in the GMPPS. Specific objectives of the study were to:

- Identify potential drivers for closing the metal flow loops efficiently by better understanding the dynamics of the GMPPS.

- Propose a future eco-cycle scenario based on the potential drivers and the eco-cycle concept, and provide suggestions for implementing this eco-cycle scenario in the real-world situation of the GMPPS.

The intention was not to predict the future, but to understand, explore, and learn about the complexity and dynamics of the GMPPS.

\section{Methods}

\subsection{The eco-cycle concept}

The eco-cycle concept (Ravetz, 2000; Eco-Cycle, 2014) represents the industrial metabolism (Fischer-Kowalski and Haberl, 1998) in a socio-technical system (Geels, 2012) where substances or resources continuously circulate within the socio-economic system with low or no leakage of the resources. The term eco-cycle is used in this study to represent nearly closed-loop material flows or very low leakage in the mobile phone product system. The conceptual eco-cycle model focuses on the technical nutrients, e.g., metals, that are circulated in the socio-technical system with little or no re-entry into the lithosphere (Graedel and Allenby, 2003; Preston, 2012).

The necessary links between actors to close the material flow loop in the GMPPS are illustrated in Fig. 1. Physically, the product system entails the extraction of necessary raw materials, production and assembly of parts by manufacturers and suppliers, a maintenance and distribution network, utilization by consumers, material collection and recycling, waste treatment, and transports. In a societal context, the system includes the behavior of markets and user practices, costs, price and demand elasticity, purposes, function and objectives, consumer preferences, awareness, economic development, and aspects of a social and a softer character.

The eco-cycle concept in mobile phone product systems thus includes both physical resource management and social aspects. In this study, the eco-cycle concept illustrated in Fig. 1 only provided the mental model to visualize the eco-cycle scenario qualitatively. The quantitative eco-cycle was formulated by experimenting with the SD model. The default SD model was parameterized based on a business as usual (BAU) scenario.

\subsubsection{Eco-cycle indicators}

Based on circularity indicators produced by the Ellen MacArthur Foundation (2015) and Bollinger (2010), two indicators were employed for examining the GMPPS. These were loop leakage and loop efficiency, which quantify the degree to which metals are efficiently preserved in the system. The loop leakage indicator, based on the linear flow index by Ellen MacArthur Foundation (2015), determines the resource fraction leaving the product system, i.e., it indicates to what extent the loop is closed and metals are preserved in the system. The loop efficiency indicator, based on the cradle-tocradle indicator (C2CI) developed by Bollinger (2010), determines how efficiently the resources are utilized in the system. In this case, efficiency indicates the efficient uses of resources without hibernating resources. Eq. (1) illustrates quantification of loop leakage 


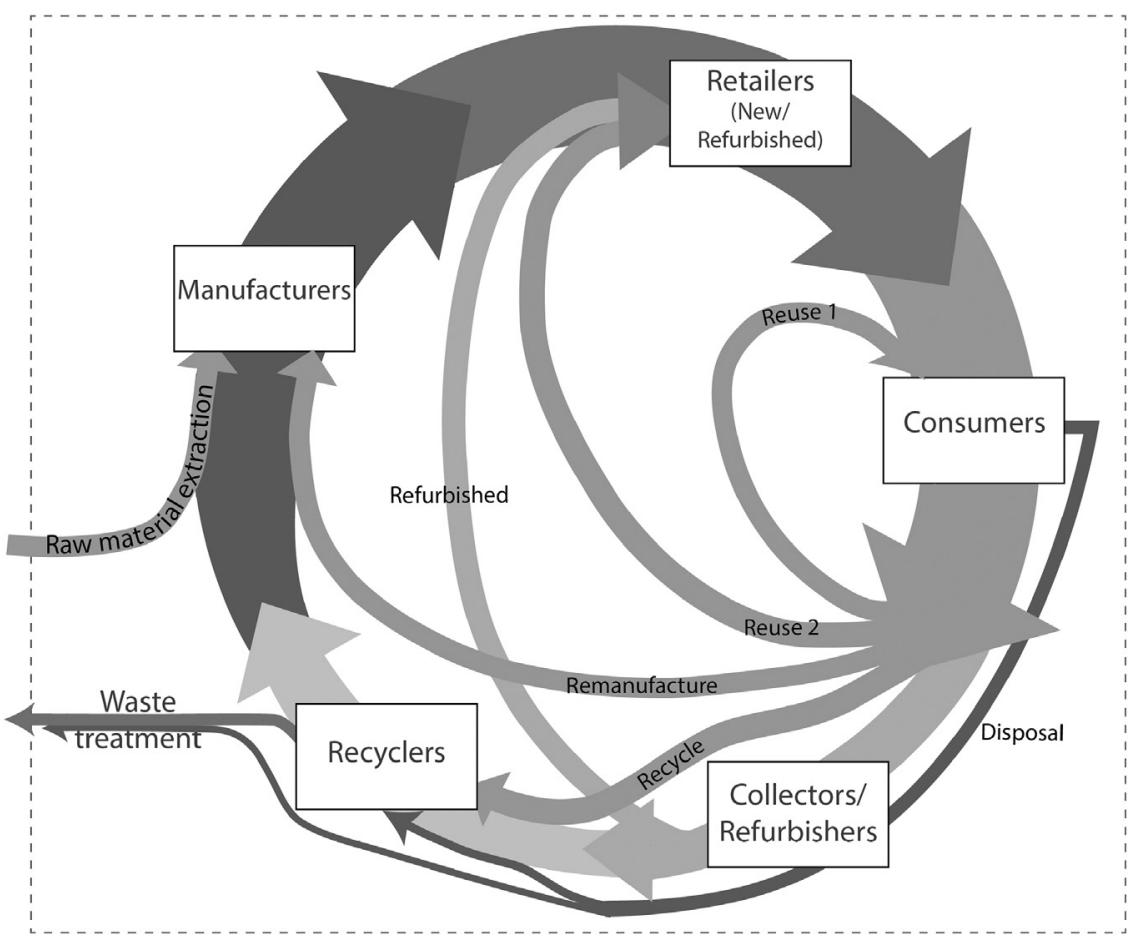

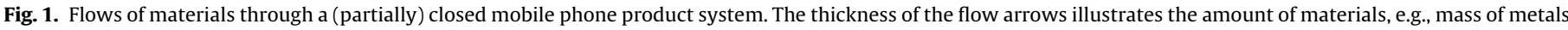
or number of phones, in industrial symbioses within the product system.

$\left(l_{m}\right)$ and loop efficiency $\left(e_{m}\right)$ in the SD model, adapted and modified from the equation for the cradle-to-cradle indicator $(\mathrm{C} 2 \mathrm{CI})$ of Bollinger (2010).

$$
\begin{aligned}
& l_{m}(t)=\frac{\sum_{t=0}^{t} m_{d}+\sum_{t=0}^{t} m_{d r}}{\sum_{t=0}^{t} m_{m}} \\
& e_{m}(t)=1-\frac{\sum_{t=0}^{t} m_{d}+\sum_{t=0}^{t} m_{d r}+m_{h}(t)}{\sum_{t=0}^{t} m_{m}}
\end{aligned}
$$

where $l_{m}(t)$ determines the loop leakage for metal $m$ at time $t ; e_{m}(t)$ is the value of loop efficiency for metal $m$ at time $t ; \sum_{t=0}^{t} m_{d}$ is the cumulative mass of metal $m$ disposed of through phones disposal at time $t ; \sum_{t=0}^{t} m_{d r}$ is the cumulative mass of metal $m$ disposed of by phone recyclers at time $t ; \sum_{t=0}^{t} m_{m}$ is the cumulative mass of metal $m$ used in phones by manufacturers at time $t$ and $m_{h}(t)$ is the amount of metal $m$ in hibernating phones at time $t$.

\subsection{System dynamics model}

The SD model was adopted from the equation-based model of Bollinger et al. (2012) to conduct metal flow analysis of the GMPPS in a life cycle perspective in order to explore an eco-cycle scenario. Fig. 2a describes the conceptual system dynamics model of the GMPPS. The arrows in the figure between subsystems represent information flows. The mobile phone flows subsystem is portrayed using system dynamics diagramming notations (Sterman, 2000), where a rectangular box represents stocks, a pipe arrow pointing to a stock represents inflows, a pipe arrow out of a stock represents outflows, valves on the pipes control the flows, clouds represent sources/sinks and each linked arrow represents a causal relation.

The overarching model of the system is divided into two main domains with similar stocks and flows, IC and DC. These two domains are connected through the export and import of used phones (Fig. 2a). The export and import of used phones between IC and DC depend on economic profits for further business, e.g., refurbishing, retail, recycling (see Appendix). The performance domain in the model (Fig. 2a) then collects all information related to stocks and flows in IC and DC to estimate the global metal balance and eco-cycle indicators (Eq. (1)).

Since the IC and DC domains have similar stocks and flows, a common detailed illustration of the stocks, flows, and subsystems of each domain is presented in Fig. 2b. In the diagram, the mobile phone flows subsystem is shown with detailed stocks, flows, and causally linked parameters, whereas other subsystems (consumer, metal flows, economy, and investments) are represented as conceptual information flows to the mobile phone flows subsystem. The consumer subsystem processes the information on consumer growth and consumer choice between purchasing an old and new phone. The metal flows subsystem provides information about metal requirements for phone manufacturing and recovery of metals. The economy subsystem processes the information on all types of costs, price-demand elasticity, and expected profits. The investments subsystems provide the information for investing or shrinking the business to specific sectors, e.g., manufacturing. These subsystems are documented in the Appendix with detailed stocks, flows, state variables and equations.

The processes in Fig. 2 were parameterized with real-world data input (see Table 1). The resulting default SD model represents a BAU scenario or base case. Based on an optimization outcome and sensitivity analysis (see Figs. 5 and 6), the eco-cycle scenario was then evaluated by varying the values of different input parameters.

\subsection{Model modification, quantification, and implementation}

Here, we implemented the system dynamic model shown in Fig. 2 in the educational version of AnyLogic 6.8.1 software (AnyLogic, 2014). We quantified the SD model based on the work of Bollinger et al. (2012) and Bollinger (2010). Detailed parameterization and description of the equations in the model are provided in the Appendix.

The investment sectors in the adopted model implemented in AnyLogic did not show results in agreement with the real-world 

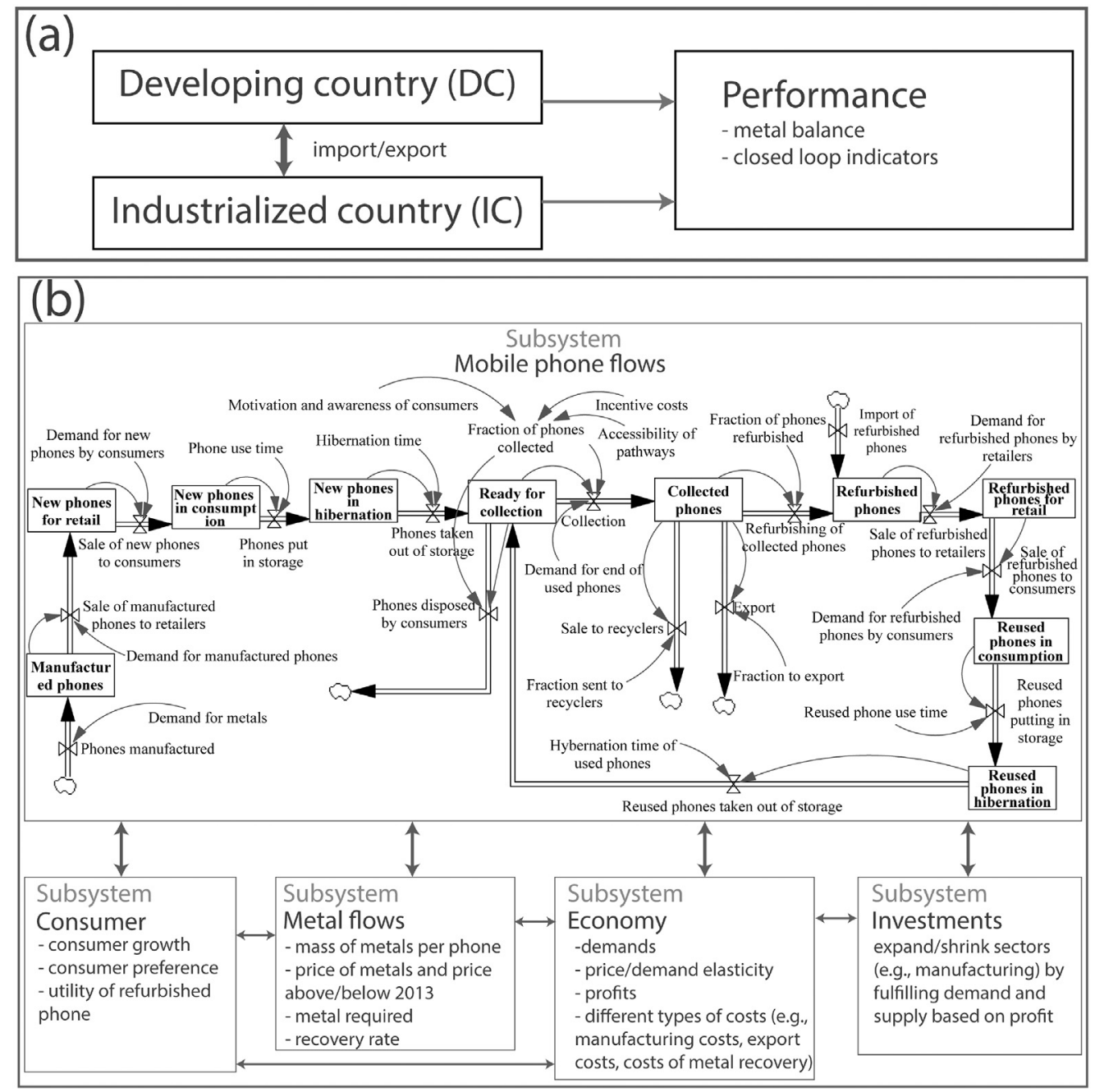

Fig. 2. (a) Conceptual system dynamics model of the global mobile phone product system (GMPPS) and (b) further illustration of each domain (industrialized countries (IC) and developing (DC)) with five subsystems.

Table 1

Default parameter values for the system dynamics (SD) model of the global mobile phone product system (GMPPS). IC=industrialized countries, DC=developing countries

\begin{tabular}{lll}
\hline Parameter & Value & Reference \\
\hline IC/DC Retail cost of phone & $7 \%$ of manufacturing cost & Bollinger et al. (2012) \\
IC/DC Phone use time & 1.5 years & Bollinger et al. (2012), Neira (2006) \\
IC/DC Phone hibernation time & 1 year & Bollinger et al. (2012), Neira (2006) \\
IC collection cost per phone & $2.25 \mathrm{USD}$ & Geyer and Blass (2010) \\
DC refurbishing cost per phone & $4.9 \mathrm{USD}$ & Bollinger et al. (2012) \\
IC cost of metal recovery per phone & $0.27 \mathrm{USD}$ & Geyer and Blass (2010) \\
DC cost of metal recovery per phone & 0.14 USD & Bollinger et al. (2012) \\
Gold recovery rate IC recyclers & 0.95 & Bollinger et al. (2012) \\
Gold recovery rate DC recyclers & 0.25 & Bollinger et al. (2012) \\
Mass of gold per phone & $0.03 \mathrm{~g}$ & Navazo et al. (2014), Geyer and Blass (2010) \\
Mass of silver per phone & $0.51 \mathrm{~g}$ & Geyer and Blass (2010) \\
Mass of copper per phone & $15 \mathrm{~g}$ & Geyer and Blass (2010) \\
Mass of palladium per phone & $0.045 \mathrm{~g}$ & Geyer and Blass (2010) \\
Price of gold per gram & 52.19 USD & Perthmint (2013) \\
Price of silver per gram & $0.91 \mathrm{USD}$ & Perthmint (2013) \\
Price of copper per gram & $0.0068 \mathrm{USD}$ & Bollinger et al. (2012) \\
Price of palladium per gram & 25.59 USD & Perthmint (2013) \\
Export cost per phone & 0.0079 & Bollinger et al. (2012) \\
Accessibility of IC/DC collection pathways & 0.5 & Bollinger (2010) \\
IC/DC consumer motivation and awareness & 0.5 & Bollinger (2010) \\
Manufacturing costs & 65.4 USD & Bollinger et al. (2012) \\
Incentive costs & 20 USD & Bollinger et al. (2012) \\
\hline
\end{tabular}


trend. Therefore, we modified the investment sectors only. According to Bollinger (2010), investors will invest if the expected profit is positive. However, it is not clear in their demonstration how investors would grow or fulfill the upstream demand, e.g., retailer or consumer demand for phones, and downstream demand, e.g., collector, refurbisher or recycler demand for phones. In our modeling approach, investors will invest based on the predicted expected profit due to the investment. If the business is profitable, the investors grow their business; otherwise, they shrink it, i.e., degrow. We also set a controlled growth rate for investors. The controlled growth determines the instantaneous growth rate based on the demand and maximum handling capacity of the investors. For instance, when the demand is high, the controlled growth encourages the investors to grow at a higher rate. See the Appendix for information on the controlled growth.

In our model, we assumed that upstream investors grow with consumer demand (i.e., investment in manufacturing and retail, see Fig. 2b) without any control. In other words, the manufacturers and new phone retailers will always fulfill the demand, without considering the instantaneous growth rate. However, the EoL organizations invest in their business with controlled growth defined by a multiplying factor which is the ratio of demand and to the maximum capacity of the organization. EoL organizations invest to grow or degrow their capacity based on the demand, current stock, the maximum handling capacity of the organization, and expected profit from the investment. Since the policy and regulations for managing e-waste are stricter in IC than in DC (Kuehr, 2012; Navazo et al., 2014), we assumed in our model that IC collection always fulfills at least $20 \%$ of collection demand. In other words, the collectors have to collect $20 \%$ of the demand for both profit and loss.

\subsection{Assumptions and limitations}

Based on statistics for the most recycled metals in EoL phones and e-wastes (Basel-Convention, 2008; Tischner, 2012; Navazo et al., 2014), we assumed that gold ( $\mathrm{Au})$, copper (Cu), silver ( $\mathrm{Ag})$, and palladium (Pd) were the metals of highest interest in the GMPPS context. These metals were assumed to be of pure quality and with constant price over time. In our model, gold is the main driver for recycling, because of its high economic value (Basel-Convention, 2008; Tischner, 2012). According to Navazo et al. (2014), the economic value of materials in EoL phones comes to $80 \%$ from $\mathrm{Au}$, $10 \%$ from Pd and $7 \%$ from Ag. Thus, our modeling of the EoL metal flows in the mobile phone product system was based on the behavior of the gold flow and gold recycling rate. The recycle rate and flow behavior of copper, silver and palladium in the mobile phone product system might not be similar to gold. The composition of materials in the phones and the production technology were assumed not to change over time in the model.

\subsection{Model inputs}

Table 1 shows the default parameter values used in the model. In the following text, default parameter settings refer to the base case which also represents the $B A U$ scenario.

In the model, the rate of phone subscriptions as a function of consumer growth (cf. Fig. 2) is taken from Fig. 3b. Initial stock values for the model are presented in Table 2. According to ITU (2013), mobile phone subscriptions in 1994 amounted to 60 million in IC and 8 million in DC. Global mobile phone subscriptions in 1994 were approximately $1 \%$ of global phone subscriptions in 2012 (ITU, 2013). Thus, the initial point in the model was set to 1994. The initial stock values shown in Table 2 were used for all experiments in this study. The study period for all experiments was
Table 2

Initial stock value for the system dynamics (SD) model of the global mobile phone product system (GMPPS).

\begin{tabular}{lrl}
\hline Stocks & \multicolumn{1}{l}{ Values } & Reference \\
\hline IC consumer & $6,000,000$ & ITU (2013), UN (2013) \\
IC new phone consumer & $42,000,000$ & Assumed (70\% of total) \\
IC refurbished phone consumer & $18,000,000$ & Assumed (30\% of total) \\
DC consumer & $8,000,000$ & ITU (2013), UN (2013) \\
DC new phone consumer & $5,600,000$ & Assumed (70\% of total) \\
DC refurbished phone consumer & $2,400,000$ & Assumed (30\% of total) \\
\hline
\end{tabular}

All other stocks are set to 0 .

1994-2050. Numerical methods and tolerances used in the model are documented in the Appendix.

\subsection{Experiments}

\subsubsection{Drivers and eco-cycle scenario}

We conducted a sensitivity analysis to identify the most sensitive parameters and assess the uncertainty and robustness of the model. The sensitivity of parameters to a certain output can indicate a dominant path and associated drivers (Sterman, 2000). In our study, a sensitivity analysis was conducted to identify the potential drivers for which the loop leakage of the system was at a minimum and the loop efficiency was at a maximum. This sensitivity analysis was performed by increasing (or decreasing) one parameter value from the base case (Table 1) by up to $100 \%$ while keeping other parameters at their default values. The values of loop leakage and loop efficiency were estimated as averages for the period 1994-2050. The sensitivity analysis was conducted considering all the input parameters shown in Table 1 . However, some parameters were omitted from the analysis based on their behavior to the loop indicators. In many processes in the model, a number of parameters showed closely resembling contribution to the process and the loop indicators. In those cases, we only took one parameter as a proxy for the others. For example, consumer motivation and awareness, accessibility of collection pathways, and incentive costs contribute positively to the fraction of phones collected, but we only considered accessibility of collection pathways in the analysis. The potential drivers were ranked based on their contribution to minimizing loop leakage and maximizing loop efficiency. The drivers were then analyzed with the system dynamics model to understand the system for the eco-cycle indicators.

Next, we devised an eco-cycle scenario focusing on maximizing loop efficiency and minimizing loop leakage using the OptQuest optimizer (AnyLogic, 2014; OptTek Systems, 2015) and manual tuning. First, we used the OptQuest optimizer to optimize both high- and low-sensitivity parameters (Figs. 5 and 6). We initially set possible maximum and minimum values for all sensitive parameters to optimize the system by maximizing loop efficiency and minimizing loop leakage. Then we narrowed down the maximum and minimum values for the parameters toward the optimized values. Finally, we carried out manual tuning to achieve the optimized values for the eco-cycle scenario, focusing on maximizing loop efficiency and minimizing loop leakage.

\subsubsection{Model testing}

First, we tested the model with causal loop and structure assessment tests (Sterman, 2000; Rahmandad and Sterman, 2012). The structure assessment tests included both direct structure and structure-oriented behavior tests. The direct structure test included relations and assumptions and relevant variables, and examined the static structure of the model. The structure-oriented behavior test examined the behavior of the model with some selected parameters and their extreme values and also in a sensitivity analysis (Figs. 5 and 6) with constant-step parameter change to check 

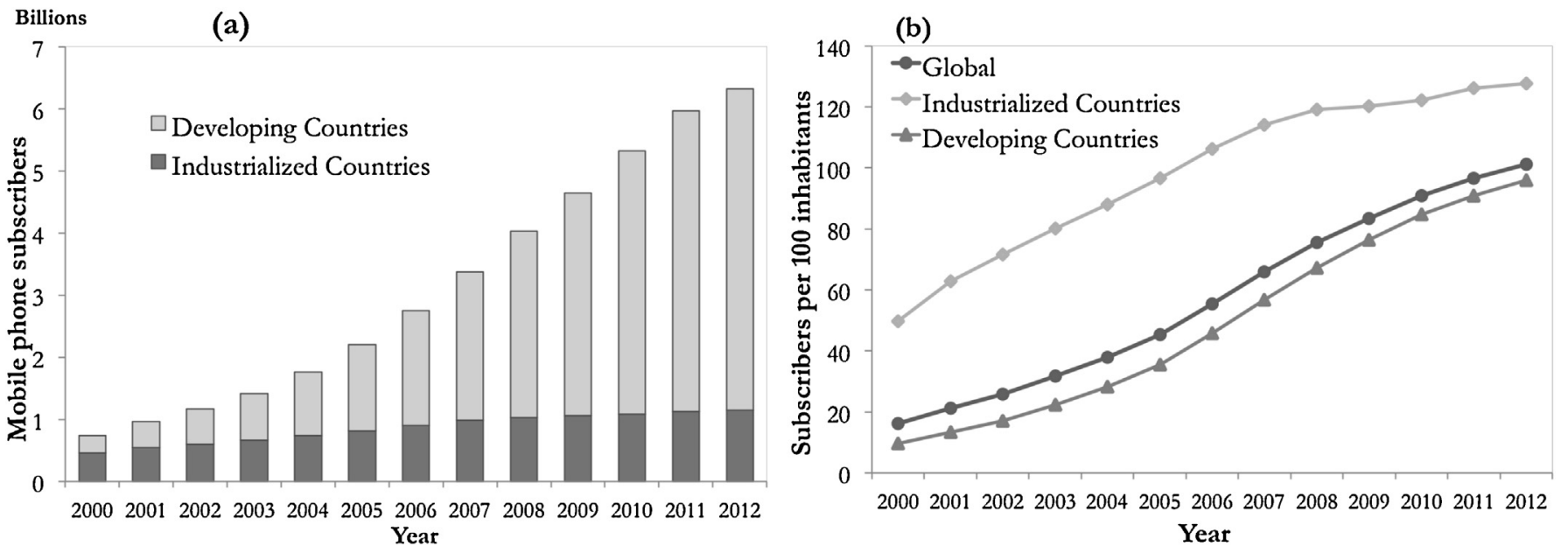

Fig. 3. Change in number of (a) mobile phone subscribers and (b) mobile phone subscribers per 100 inhabitants over time, $2000-2012$. Data source: ITU (2013).

the behavior. Extreme conditions were tested to inspect the equations for extreme values and the plausible response when subjected to extreme values of the parameters. This test examined the model behavior no matter how extreme the policy would be to impose. For example, we checked $100 \%$ collection of phones, no phone hibernation time, no recycling costs, and so on. The model showed agreement with the results in the causal loop tests and structure assessment tests.

We then tested the model with model-independent real world data, i.e., field data, on consumer growth and EoL scenario. Fig. 4 shows the modeled number of mobile phone subscriptions (solid lines) for IC, DC, and globally as a function of time from 1994 to 2012. In the simulations, the initial (1994) number of subscriptions was set to $6,000,000$ and $8,000,000$ for IC and DC, respectively (ITU, 2013) and the input to the model was the global population (taken from UN (2013)). Markers in Fig. 4 show modelindependent observations of number of subscriptions from the literature shown in Fig. 3a. The result showed that the model was able to replicate the observed historical behavior of mobile phone subscriptions. The average deviation during 2000-2012 between modeled and observed number of global subscriptions was around $3 \%$ and the average deviation during 2006-2012 was less than $1 \%$

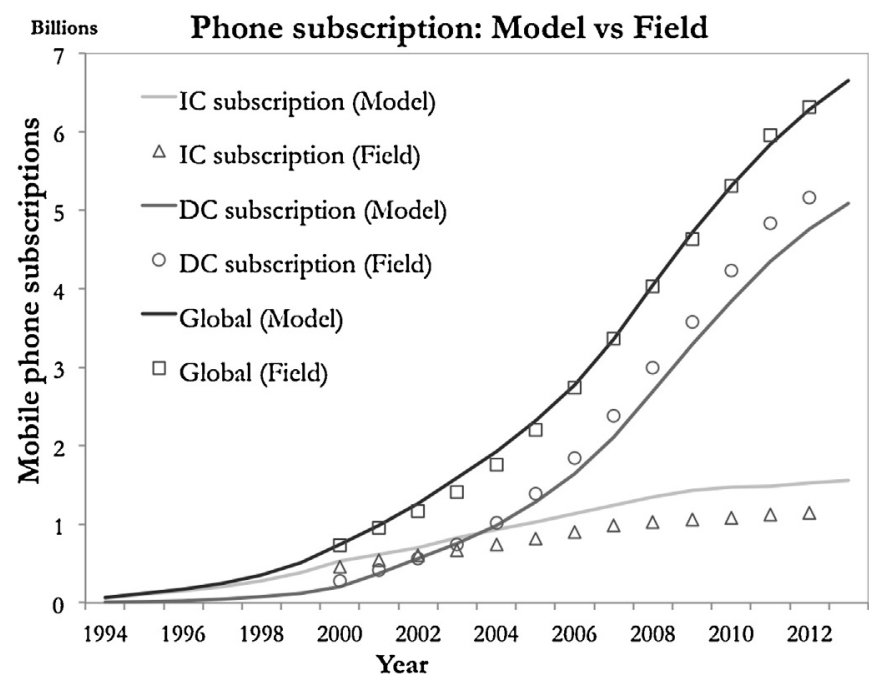

Fig. 4. Global industrialized country (IC) and developing country (DC) phone subscriptions over time, 1994-2012. Symbols show estimates from the literature (ITU, 2013), while solid lines show model output from this study. (see Appendix). We considered this level of agreement satisfactory for the purposes of this study.

Table 3 shows the EoL scenarios for the IC using model results (BAU case) and data for real world situations (i.e., field data). These field data were collected from different publications and represented the range between minimum and maximum values found in the literature (see Table 3). The quality of these field data was sometimes not transparent as regards e.g., estimation methods. Furthermore, due to unavailability of data for some countries, the data represent the statistical average of only a few IC.

The model results for hibernation, disposal, export, and reuse fell within the range of field data but the values obtained for collection and recycling were higher than the field values. There was significant uncertainty in the field values for IC as regards recycling (2-16\%) and disposal (53-90\%). Since the disposal value given by the model was close to the lower boundary of the field data range (53\% in Table 3), this resulted in higher model values for collection and recycling. Considering the quality and unavailability of the data discussed above, we considered model performance satisfactory for the purposes of the study.

\section{Results and discussion}

\subsection{Potential drivers}

Potential drivers were identified by the sensitivity of the parameters to loop leakage and loop efficiency. Loop leakage represents to the extent to which metals leave the global mobile phone product system, while loop efficiency determines how efficiently the resources are utilized in the system (Eq. (1)). Figs. 5 and 6 show the response in global loop leakage (Figs. 5a and 6a) and loop efficiency (Figs. 5b and 6b) to individual changes in selected parameters of the model. The base case represents the business as usual (BAU) parameter setting in the model, using best estimates of parameter values. With changes in the selected parameter values, the DC parameters showed larger contribution to the loop leakage and the loop efficiency than the IC parameters (Figs. 5 and 6). Based on the larger contribution to minimize the loop leakage, we devised the following parameter ranking upon a $100 \%$ increase in the parameter values: (i) accessibility of collection pathways (i.e., collection system) for both IC and DC; (ii) mobile phone use time (i.e. life span) for both IC and DC; (iii) gold recovery in DC; and (iv) mobile phone hibernation for both IC and DC. The analysis also suggested the same parameter ranking for loop efficiency (Figs. 5b and 6b), which was based on the contribution to maximize the loop efficiency by changing 
Table 3

Industrialized countries (IC) end of life (EoL) scenarios for model testing.

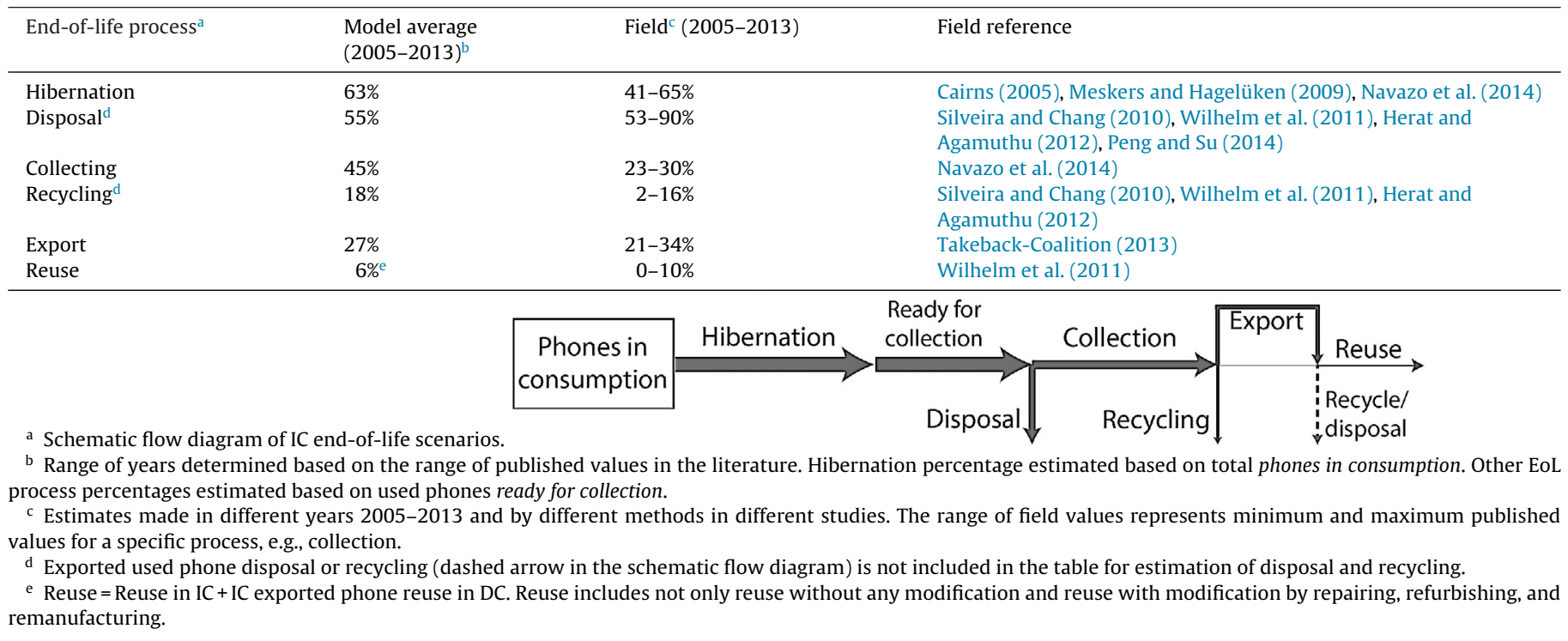

all selected parameters $100 \%$ from the base case. An increase in the above ranked parameters from the base case, which was based on a best estimate of the current situation (2013), led to a decrease in the loop leakage (Figs. 5a and 6a) and an increase in the loop efficiency except for the IC and DC phone hibernation time (Figs. 5b and 6b).

We also analyzed the drivers through the SD model to gain insights into eco-cycle indicators. This revealed that the accessibility of collection pathways and mobile phone use time made the largest contributions to closing the loop efficiently (Fig. 5). Based on the causal relationship in the model, longer life of phones reduces the demand for new phones. As a result, manufacturers require less metal for new phone production. In addition, longer use time of a phone delays EoL management and increases the collection rate because of the lower number of phones ready for collection. Consequently, consumer disposal rate of phones outside collection systems decreases. In the model, collection of phones was estimated by: (i) accessibility of collection pathways; (ii) consumer motivation and awareness; and (iii) incentives for consumers (see Fig. 2b and equations in Appendix). Since accessibility of collection pathways (Fig. 5) made a larger contribution to the closed loop system, a higher collection rate can be achieved by incentives to consumers or by educating them to increase awareness.

According to the SD model, more efficient collection of phones enhances the positive feedback loop toward an efficient closed loop system through the refurbish, reuse, and recycle paths (cf. the loop in mobile phone flows subsystem in Fig. 2b). In addition, a higher collection rate makes the business profitable, which attracts more investors to invest. Therefore, an efficient collection system enhances the EoL organizations (e.g., collection, recycle) to grow and initiate synchronized growth with upstream parts of the product system. Synchronized growth is further discussed in conjunction with results of the eco-cycle scenario.

Experiments with the model on a higher degree of collection showed higher exports (c.f. Fig. 2b) of used phones from IC to DC. The recovery rate of informal recycling in DC was very low compared with the rate in IC (cf. Table 1). Consequently, the informal recycling sectors created system leakage, showing higher leverage in the sensitivity analysis (cf. gold recovery rate DC recyclers in Fig. 5). This suggests a need to improve the recycling efficiency, especially in informal sectors in DC.

The last dominant driver according to the model, hibernation of phones, resulted in decreased loop leakage with an increase in hibernation time (cf. DC phone hibernation time in Fig. 5a). However, longer hibernation of phones also decreased loop efficiency (cf. IC and DC phone hibernation in Fig. 6b). Thus, the model indicates that short duration of phone storage (without any use) increases loop efficiency.

A negligible contribution to loop leakage and loop efficiency in both IC and DC (Figs. 5 and 6) was observed with an increase in the following parameters: manufacturing cost, export cost, utility of a refurbished phone, i.e., functionality compared with a new phone, and price of metals.

Surprisingly, an increase in manufacturing costs from the base case made a very small contribution to eco-cycle indicators (cf., manufacturing costs in Fig. 5a and b). However, a decrease from the base case made a moderate contribution to eco-cycle indicators. Very low manufacturing costs of phones (Fig. 5) increased loop leakage and decreased loop efficiency. According to the model, consumers buy new phones by comparing the price and utility of a new phone and a secondhand phone. Among cheaper phones, consumers generally prefer buying new phones over secondhand phones, and this decreases the reuse of phones. Eventually, the phones are discarded, and the life span of phones becomes shorter. Thus, cheaper phones (i.e., lower manufacturing costs) resulted in large loop leakage and low loop efficiency (cf., manufacturing costs in Fig. 5a and b).

On the other hand, for phones with higher manufacturing costs, e.g., high end smartphones, an increase from the base case made a negligible contribution to loop leakage and loop efficiency (cf. Fig. 5). According to the model, a possible explanation is less profit for recyclers to buy those phones to recycle. As a result, the phones are not attracted to the collection systems at their EoL. The costly phones thus act like a default phone in the model. Moreover, the model does not have any direct price feedback on reuse and life span of a phone.

Among other drivers in the model, cost of metal recovery (Fig. 6) surprisingly made a negligible contribution to loop leakage and loop efficiency. According to the model, the formal recycling is not profitable in the BAU scenario (base case). In addition, with a change (increase/decrease) in the cost of metal recovery, formal recycling is not still profitable, because the recovery cost is a very small part of the total upstream costs associated with the collection of EoL phones by the formal facility. As a result, most EoL phones end up at an informal facility, and the change in the cost does not affect 

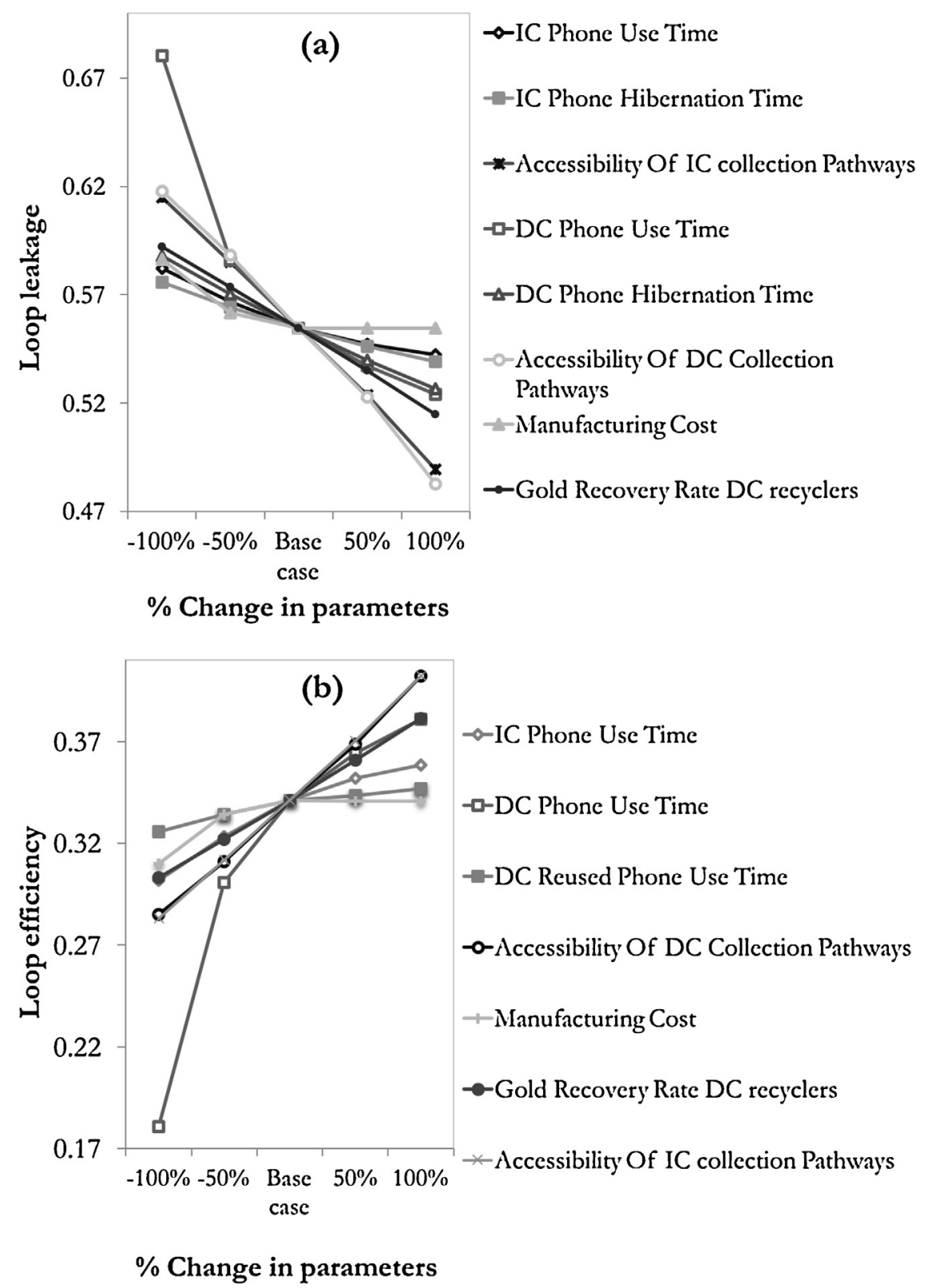

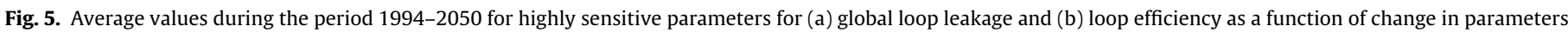
from base case.

EoL phone flows, or loop leakage and loop efficiency. Another reason could be that EoL phones are not accessible to the collection system, e.g., consumers are not aware of the need to recycle their EoL phones, which does not have any link to the recovery cost in the model. Eventually, the consumers either hibernate phones or throw them away as usual. Other parameters that made a negligible contribution to loop leakage and loop efficiency in both IC and DC (Figs. 5 and 6) were: export cost, utility of a refurbished phone, and price of metals.

While the model assumed that all new phones have the same material composition and functionality, the results of the sensitivity analysis indicate that the model can interpret differences in behavior for smartphones (i.e., high manufacturing costs) and cheaper phones. Similarly, the model can explain other assumptions, such as increasing metal prices and changing recovery technology.

In order to improve the model, it is recommended to investigate feedback loops to increase life span of mobile phones since the model does not have any direct feedback on life span. It is also important to explore the influence of the environmental concerns of consumers to improve collection systems as well as to increase life span of phones. Future studies could also focus on investigating whether resource scarcity or criticality of materials (EU, 2010) could close the material flow loop since (i) the rising demand of raw materials is surpassing supply; and (ii) some minerals are only produced in a few countries.

\subsection{Eco-cycle scenario}

Parameter settings suggested for the eco-cycle scenario based on results from the optimization and the sensitivity analysis are shown in Table 4 and EoL scenarios in IC and DC for BAU and ecocycle parameter settings at steady state over time 1994-2050 are shown in Table 5 . The BAU scenario in Table 5 shows the steady state values for default or base case parameter settings and the eco-cycle scenario shows the steady state values for the eco-cycle 


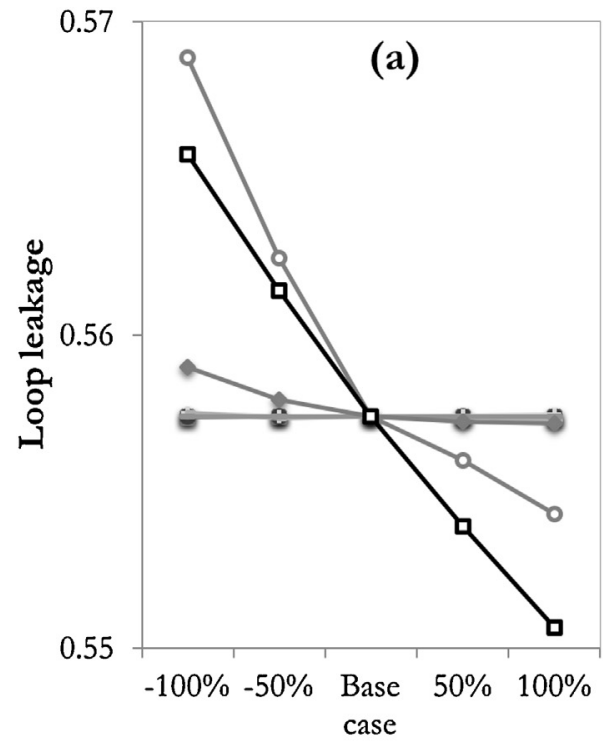

\author{
- IC Reused Phone Use Time \\ *-IC Reused Phone Hibernation Time \\ $\rightarrow-$ Export Cost \\ - Cost Of Metal Recovery \\ -Utility Of Refurbished Phone \\ $\leadsto$-Metal Price Above/Below 2013 Price \\ -o-DC Reused Phone Use Time
}

$\%$ Change in parameters

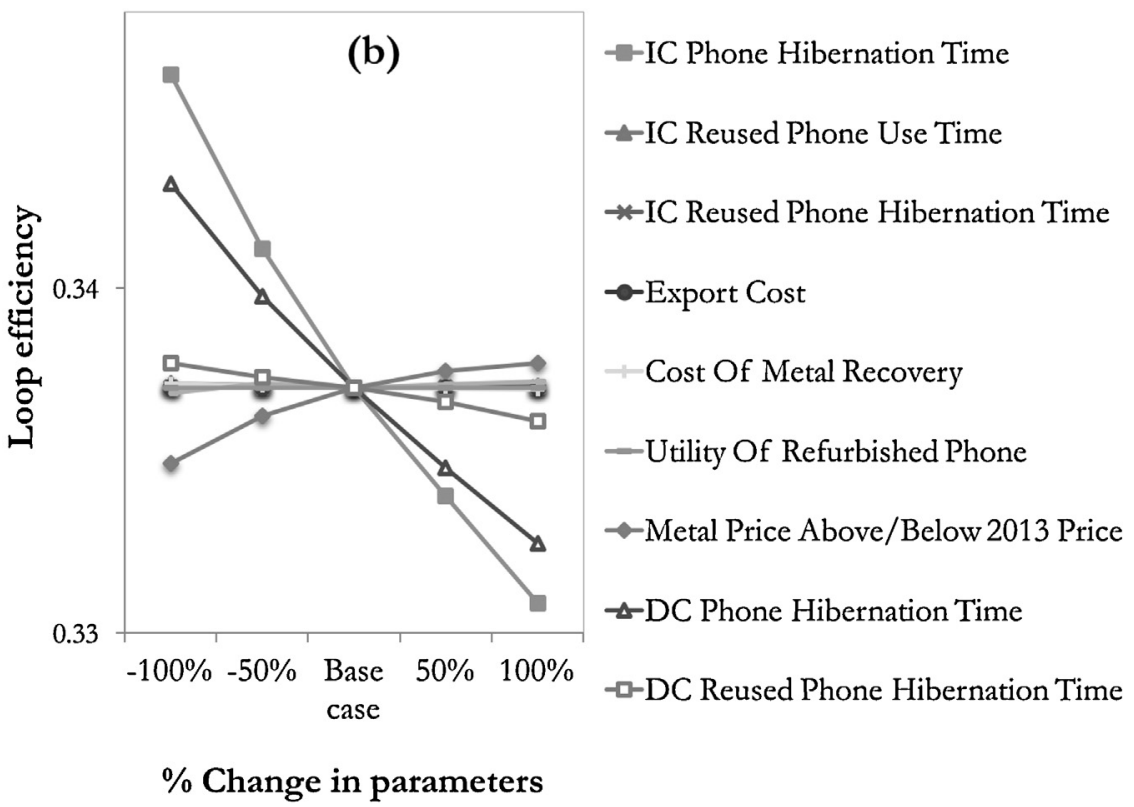

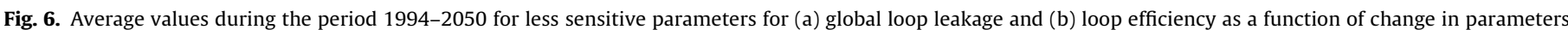
from base case.

parameter settings. In the eco-cycle scenario, a step change from BAU to eco-cycle parameter settings was introduced at the year 2014. The BAU scenarios for both IC and DC, shown in Table 5, comprised 55\% disposal and hibernation of phones, which was mainly

\section{Table 4}

Suggested parameter settings for the eco-cycle scenario based on results from model optimization and sensitivity analysis. Values within brackets represent the business as usual (BAU) or base case.

\begin{tabular}{ll}
\hline Parameter & Eco-cycle \\
\hline $\begin{array}{l}\text { New mobile phone use time in both IC } \\
\text { and DC }\end{array}$ & 5 years (1.5 years) \\
$\begin{array}{l}\text { New mobile phone hibernation } \\
\quad \text { without any use in both IC and DC }\end{array}$ & 0.25 years (1 year) \\
$\begin{array}{l}\text { Accessibility of collection pathways in } \\
\text { both IC and DC }\end{array}$ & $100 \%(50 \%)$ \\
$\begin{array}{l}\text { Consumer awareness in both IC and DC } \\
\text { Gold recovery rate of DC recyclers }\end{array}$ & $75 \%(50 \%)$ \\
\hline
\end{tabular}

responsible for increasing system leakage and decreasing the efficiency (Eq. (1)). Disposal and hibernation of phones are both linked to collection systems for phones, where the BAU scenario for both country domains comprised around $45 \%$. The eco-cycle scenarios

Table 5

End-of-use phones at steady state in industrialized countries (IC) and developed countries (DC).

\begin{tabular}{|c|c|c|c|c|}
\hline \multirow[t]{2}{*}{ EoL mobile phones ${ }^{\mathrm{a}}$} & \multicolumn{2}{|c|}{ Business as usual } & \multicolumn{2}{|c|}{ Eco-cycle } \\
\hline & IC & DC & IC & DC \\
\hline Hibernation & $66 \%$ & $66 \%$ & $5 \%$ & $5 \%$ \\
\hline Disposal & $55 \%$ & $55 \%$ & $0 \%$ & $0 \%$ \\
\hline Collection & $45 \%$ & $45 \%$ & $100 \%$ & $100 \%$ \\
\hline Export & $26 \%$ & $0 \%$ & $59 \%$ & $0 \%$ \\
\hline Recycling & $18 \%$ & $26 \%$ & $41 \%$ & $68 \%$ \\
\hline Reuse & $0 \%$ & $20 \%$ & $0 \%$ & $32 \%$ \\
\hline
\end{tabular}

a cf. the schematic flow diagram in Table 3. 

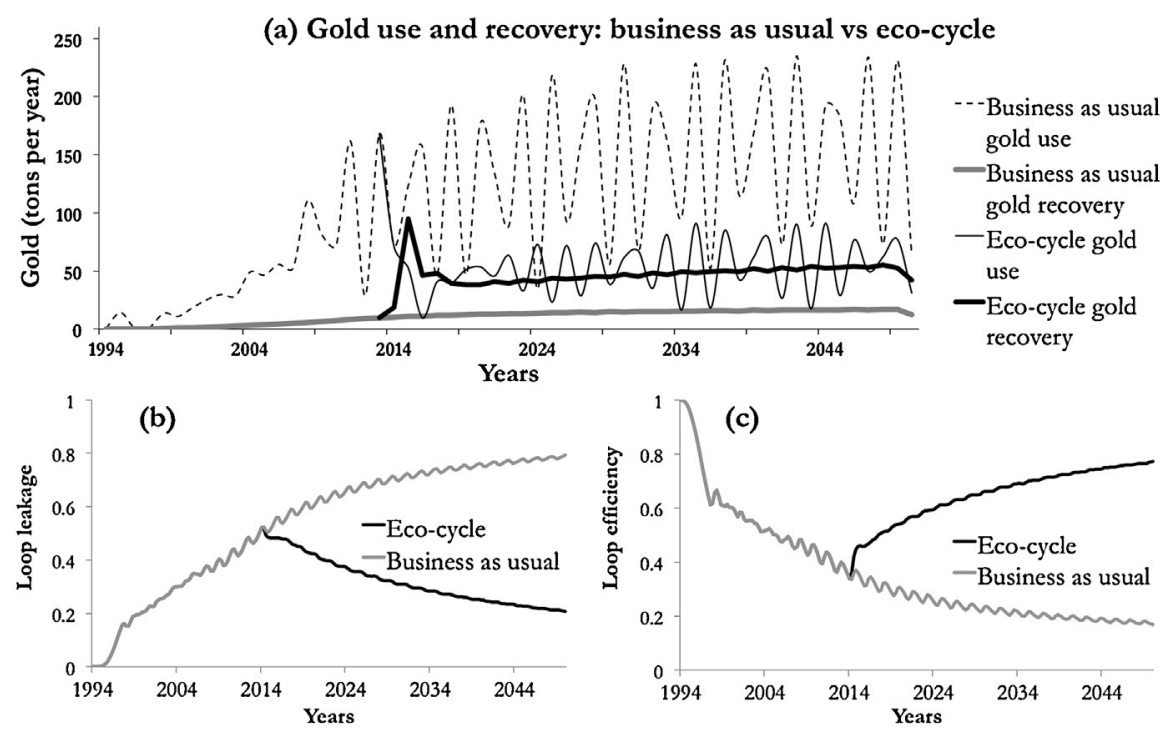

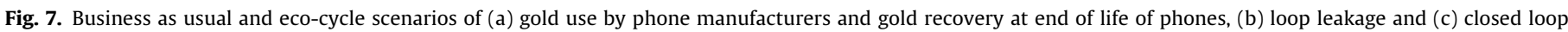
efficiency of the global mobile phone product system as a function of time during 1994-2050.

for both IC and DC showed 100\% collection of phones and, consequently, the disposal and hibernation of phones was around $0 \%$ and $5 \%$, respectively (Table 5 ). The scenario also showed that higher numbers of collected phones in eco-cycle scenarios than in BAU scenarios increases the number of recycled and refurbished/reused phones. According to the model, exported IC used phones are either recycled or refurbished/reused in DC (Table 5). Thus the suggested eco-cycle scenario could improve the EoL management of mobile phones.

We also investigated the extent to which the proposed eco-cycle scenario could contribute to recovery of material at EoL and raw material use for production of new phones. In addition, we investigated loop leakage and loop efficiency for the GMPPS. Fig. 7a shows modeled gold use and recovery from 1994 to 2050. From 1998 to 2014, the model results show increasing gold use (broken line in Fig. 7a) and a low rate of gold recovery (thick gray line). The oscillation in modeled gold use, particularly seen from year 2008 an onward, is ascribed to price elasticity, meaning that when prices of phones decrease, demand of phones increase, and vice versa. During the historical period 1994-2014, recovery of gold (thick gray line in Fig. 7a) as given by the model was low.

For the period 2014 to 2050 , we experimented with two alternative scenarios, BAU (broken and thick gray lines) and eco-cycle (thin and thick black lines in Fig. 7a). In the eco-cycle scenario, the period 1994-2013 shows business as usual parameter settings and the period 2014-2050 shows eco-cycle parameter settings. This experimentation was done by making a step change in parameter values for the eco-cycle scenario, where-after parameter values were kept constant over time. Thus, the model do not consider the time taken to go from BAU to eco-cycle conditions, by implementing policies and adapting new business and user behaviors in real life. Therefore, the model output cannot be seen as a dynamic prediction of future, but can never the less be used to compare BAU and eco-cycle consequences.

Model results in Fig. 7a showed a lower gold use in the eco-cycle (thin line) than in the BAU (broken line). Also, the amplitude, due to price elasticity, was lower in eco-cycle than in BAU. Moreover, the modeled gold recovery was 3-4 times larger in the eco-cycle (thick black line in Fig. 7a) than in the BAU (gray line) scenario. Therefore, we conclude, that altogether, model results suggested that eco-cycle could lessen the pressure on gold and probably other raw materials, as compared to BAU.
We also evaluated the BAU and eco-cycle scenarios in terms of loop leakage (Fig. 7b) and loop efficiency (Fig. 7c) indicators for closed loop performance of the product system. In the BAU scenario, the model showed current loop leakage to be approximately 50\% and closed loop efficiency approximately 35\%. Over time (cf. business as usual scenario in Figs. 7b and c), loop leakage continuously increased and loop efficiency decreased and by 2050 were approximately $80 \%$ and $16 \%$, respectively. On the other hand, the suggested eco-cycle scenario showed decreasing loop leakage down to approximately $20 \%$ by 2050 and increasing loop efficiency, up to around $77 \%$ by 2050 (cf., eco-cycle scenario in Figs. $7 \mathrm{~b}$ and c).

\subsection{Suggestions for an eco-cycle system}

\subsubsection{Increasing life-span of a mobile phone}

The model results indicated that a longer life-span of mobile phones (i.e., phone use time) decreases loop leakage and increases loop efficiency in the GMPPS. Improvement to a small part of a phone currently makes the whole phone obsolete because of its non-modular design (Brezet and Van Hemel, 1997, p. 155). Thus solution such as the phoneblok concept (Phonebloks, 2013) could increase the life-span of a mobile phone. Furthermore, resource conservative manufacturing (ResCoM) (Rashid et al., 2013; Asif et al., 2012) could increase the product life by allowing replacement of obsolete/damaged/expired components.

On the other hand, socio-economic enterprises (for example charities, voluntary organizations, non-profit companies, used phone sellers) play a significant role in reuse (Ongondo et al., 2013) of a phone for extending its life. In this case, Ongondo et al. (2013) suggest a resource platform by creating industrial byproduct symbiosis for fostering reuse, recycling, and EoL management.

\subsubsection{Enhancing collection and end-of-life}

Our modeling results suggested that improved collection systems for used mobiles is a key driver for the eco-cycle scenario that could synchronize growth between upstream and downstream activities. Organizations/sectors/technical systems at the EoL are currently not growing in synchronization with new phone production in order to handle used phones. Hence, more investment at EoL is required to synchronize growth of upstream and downstream sectors, in order to achieve an efficient, circular material flow loop. In the real world and in the model, an organizational growth engine 
depends on profit, which triggers investment, creating a positive feedback loop (Laurenti et al., 2015b) for the organization/business growth. To close the material flow loop and for the eco-cycle scenario in the GMPPS, synchronized growth of production, consumption, and EoL management is essential.

To promote synchronized growth, it has been suggested that upstream producers include external costs (e.g., social and environmental costs of production and EoL management) in producing their products (Leonard and Conrad, 2011; Jackson, 2011; Laurenti, 2013; Liao and Chuang, 2013). In addition, extended producer responsibility (EPR) could play an important role in internalizing EoL costs and possibly promoting improved collection (Herat and Agamuthu, 2012; Corsini et al., 2013; Laurenti et al., 2015b). At the same time, an EPR could motivate producers to design phones with better recycling characteristics (Corsini et al., 2013; Herat and Agamuthu, 2012; Besiou et al., 2012), which could increase recovery rate. Based on a concept of designing phones with better recycling characteristics and securing a longer life-span, Laurenti et al. (2015b) devised a product service system (PSS) that could create a new circular growth (e.g., reusing, refurbishing, recycling) at the EoL of mobile phones. Kuehr (2012) also argues that PSS could close the loop avoiding loop leakage and illegal shipment of e-waste. Overall, therefore, internalizing external costs, EPR, and PSS could synchronize growth by improving collection systems.

Based on the discussion above, PSS could synchronize growth of the EoL and the upstream production of mobile phones, which is essential for creating a closed loop in the mobile phone product system. In this context, Shokohyar et al. (2012), Shokohyar et al. (2013) suggested some leasing strategies in PSS that could increase loop efficiency and minimize waste generation during the product life cycle, as well as minimizing loop leakage. A reverse supply chain and various recycling steps (Kuehr, 2012) could be other solutions for preventing system leakage and increasing loop efficiency. Introduction of reverse logistics with the opening secondary markets for refurbished/second-hand phones (i.e., the resource platform proposed by Ongondo et al. (2013)) could increase the reuse of phones. In addition, the opening of secondary markets could reduce the preference for purchasing new phones over functional secondhand phones, i.e., rationalize consumer choice between old and new phones.

Waste policies or implementation of related legislation have a significant influence on e-waste management (Widmer et al., 2005). However, introducing policy to reduce waste in one system could shift the burden to the other systems. For example, implementation of strict e-waste guidelines could increase the cost of formal recycling due to legal requirements on waste treatment and disposal of hazardous material and this might increase the materials flow to informal recycling facilities, where recovery of valuable materials is less efficient because of primitive technology. Therefore, policy makers should apply broader systems thinking before implementing legislation. On national level, policy incentives to improve collection systems could amplify the reverse logistics of used phones, as discussed above. In addition, imposing an increased tax on material and embedded energy, and a decreased tax on labor, could help grow the repair and refurbishment sectors, which can extend the life span of phones (Cooper, 2012). Furthermore, policy support at national or global level could allow the PSS to shape sustainable production and consumption in the GMPPS. To sum up, policy to promote PSS or/and reverse logistics could help close the metal flow loop in the GMPSS and support to promote a circular economy.

\section{Conclusions}

Because of the rapid obsolescence of mobile phones and associated technologies, disposal of phones has increased, placing increasing pressure on non-renewable resources such as gold. This study investigated the possibilities to close the material flow loop for the valuable metals used in mobile phones by identifying potential drivers in the GMPPS. Previous modeling studies on mobile phone product systems have applied either qualitative and static quantitative approaches or small-scale quantitative dynamic approaches in such work, but in this study system dynamics (SD) modeling taking a broader systems perspective was applied. In implementing the SD model, an equation-based model was tested with real-world data from the scientific literature and shown to comply with analytical objectives.

The potential drivers toward an efficient closed loop system were identified in the following order to take decision on: (i) improving collection systems, (ii) used phones longer mobile phone use time; (iii) improved informal recycling in developing countries; and (iv) shorter mobile phone hibernation time. An efficient collection system would facilitate reuse, refurbishment, and recycling. The longer mobile phone use time driver reduced the pressure on the demand side for producing new phones and the pressure on EoL management. Longer mobile phone storage time without any use increased hibernation, which made the loop inefficient and increased the loop leakage. The informal recycling in developing countries driver resulted in lower resource recovery and higher systems leakage. Other drivers, such as manufacturing cost, export cost, and utility of a refurbished phone made very small contributions to loop leakage or loop efficiency.

Based on potential drivers, an eco-cycle scenario was proposed to lower pressures on resources by decreasing resource demands for production and increasing resource recovery at EoL of mobile phones. By 2050, the proposed scenario decreased loop leakage to approx. 20\% (BAU scenario: approx. 50\% at 2014 and $80 \%$ at 2050) and improved loop efficiency to around 77\% (BAU scenario: approx. $35 \%$ at 2014 and $16 \%$ at 2050). Internalization of external costs, extended producer responsibility, a resource platform concept, modular design of phones, and improved recycling efficiency could guide the current system toward the proposed eco-cycle scenario. Better policy support, development of product service systems, and introduction of reverse logistics are other potentially important measures in fostering a circular economy.

\section{Acknowledgements}

We thank PhD candidate L. Andrew Bollinger (Faculty of Technology, Policy and Management, Delft University of Technology) for his support with implementing the model. We also express our gratitude to Prof. Josepha Potting (KTH) and Per Jakobsson (KTH) for their constructive comments on the manuscript. Furthermore, Rajib Sinha gratefully acknowledges Industrial Ecology, KTH (Royal Institute of Technology, Stockholm, Sweden) for financial support. In addition, Rafael Laurenti and Jagdeep Singh acknowledge financial support from the European Commission under the Erasmus Mundus External Cooperation Windows 'EU-Brazil STARTUP' and 'India4EU' programmes.

\section{Appendix A. Supplementary data}

Supplementary data associated with this article can be found, in the online version, at http://dx.doi.org/10.1016/j.resconrec.2016. 05.010 .

\section{References}

Achachlouei, M.A., 2015. Exploring the Effects of it on Environmental Assessment: From Life Cycle Assessment of Complex Systems Modeling. Ph.D. thesis, Department of Sustainable Development, Environmental science and Engineering (SEED), KTH Royal Institute of Technology, Stockholm, Sweden. 
Andarani, P., Goto, N., 2013. Potential e-waste generated from households in Indonesia using material flow analysis. J. Mater. Cycles Waste Manage., 1-15. AnyLogic, 2014. Multimethod simulation software, Available at: http://www. anylogic.com (accessed 21.03.14).

Asif, F.M., Bianchi, C., Rashid, A., Nicolescu, C.M., 2012. Performance analysis of the closed loop supply chain. J. Remanuf. 2 (1), 1-21.

Asif, F.M., Rashid, A., Bianchi, C., Nicolescu, C.M., 2015. System dynamics models for decision making in product multiple lifecycles. Resour. Conserv. Recycl. 101, 20-33.

Asif, F.M.A., 2011. Resource Conservative Manufacturing: A New Generation of Manufacturing. (Ph.D. thesis), KTH

Basel-Convention, 2008. Guidance Document on the Environmentally Sound Management of Used and End-of-life Mobile Phones, Prepared by Mobile Phone Working Group, (online), available at: http://archive.basel.int/industry/ mppi/MPPI (accessed 07.08.13).

Besiou, M., Van Wassenhove, L., Williams, I., Ongondo, F., Curran, T., O'Connor, C., Yang, M.-Y., Dietrich, J., Marwede, M., Gallo, M., Arnaiz, S., Woolman, T., Kopacek, B., Obersteiner, G., 2012. Enablers and barriers for producer responsibility in the electrical and electronic equipment sector. In: Conference Publications. Electronics Goes Green 2012+ (EGG), Berlin.

Bollinger, L., 2010. Growing cradle-to-cradle metal flow systems: an application of agent-based modeling and system dynamics to the study of global flows of metals in mobile phones. (Master thesis at Industrial Ecology) Delft University of Technology, Delft, Netherlands.

Bollinger, L.A., Davis, C., Nikolić, I., Dijkema, G.P., 2012. Modeling metal flow systems. J. Ind. Ecol. 16 (2), 176-190.

Brezet, H., Van Hemel, C., 1997. Ecodesign: A Promising Approach to Sustainable Production and Consumption. United Nations Environment Programme, ISBN 92-807-1631X.

Cairns, C.N., 2005. E-waste and the consumer: improving options to reduce, reuse and recycle. In: Proceedings of the 2005 IEEE International Symposium on Electronics and the Environment, 2005. IEEE, pp. 237-242.

Cooper, T., 2012. Longer Lasting Products: Alternatives to the Throwaway Society. Gower Publishing Ltd.

Corsini, F., Rizzi, F., Gusmerotti, N.M., Frey, M., 2013. Extended producer responsibility and the evolution of sustainable specializations: evidences from the e-waste sector. Bus. Strategy Environ., http://dx.doi.org/10.1002/bse.1831.

Eco-Cycle, 2014. Eco-cycle: Building Zero Waste Communities (online), available at: https://www.ecocycle.org/index.php (accessed 21.03.14)

Ellen MacArthur Foundation, 2015. Circularity indicators: an approach to measuring circularity. Methodology (online), available at: http://www. ellenmacarthurfoundation.org/assets/downloads/insight/CircularityIndicators_Methodology_May2015.pdf (accessed 26.11.15).

EU, 2010, July. Critical Raw Materials for the eu. Report of the Ad-hoc Working Group on Defining Critical Raw Materials. Ad-hoc Working Group, pp. 84

Fischer-Kowalski, M., Haberl, H., 1998. Sustainable development: socio-economic metabolism and colonization of nature. Int. Soc. Sci. J. 50 (158), 573-587.

Geels, F.W., 2012. A socio-technical analysis of low-carbon transitions: introducing the multi-level perspective into transport studies. J. Transp. Geogr. 24, 471-482.

Georgiadis, P., Besiou, M., 2008. Sustainability in electrical and electronic equipment closed-loop supply chains: a system dynamics approach. J. Clean. Prod. 16 (15), 1665-1678.

Georgiadis, P., Besiou, M., 2010. Environmental and economical sustainability of WEEE closed-loop supply chains with recycling: a system dynamics analysis. Int. J. Adv. Manuf. Technol. 47 (5-8), 475-493.

Geyer, R., Blass, V.D., 2010. The economics of cell phone reuse and recycling. Int. J. Adv. Manuf. Technol. 47 (5-8), 515-525.

Graedel, T.E., Allenby, B.R., 2003. Industrial Ecology, 2nd ed. Prentice Hall, Upper Saddle River, NJ.

Herat, S., Agamuthu, P., 2012. E-waste: a problem or an opportunity? Review of issues, challenges and solutions in Asian countries. Waste Manage. Res. 30 (11), 1113-1129.

ITU, 2013. International Telecommunication Union: Statistics (online), available at: http://www.itu.int/en/ITU-D/Statistics/Pages/stat/default.aspx (accessed 31.07.13).

Jackson, T., 2011. Prosperity Without Growth: Economics for a Finite Planet. Earthscan Publications, Ltd., Routledge, ISBN-13: 978-1849713238.

Kuehr, R., 2012. Global e-waste initiatives. In: Goodship, V., Stevels, A. (Eds.), Waste electrical and electronic equipment (WEEE) handbook No, 30 in Woodhead Publishing Series in Electronic and Optical Materials. Woodhead Publishing Ltd., pp. 3-16 (Chapter 1).

Laurenti, R., 2013. Applications of Systems Thinking Within the Sustainability Domain: Product Design, Product Systems and Stakeholder Perspectives. (Licentiate thesis at Industrial Ecology) KTH Royal Institute of Technology Stockholm, Sweden.

Laurenti, R., Singh, J., Sinha, R., Frostell, B., 2015a. Towards addressing unintended environmental consequences: a planning framework. Sustain. Dev. doi:10.1002/sd.1601.

Laurenti, R., Singh, J., Sinha, R., Potting, J., Frostell, B., 2015b. Unintended environmental consequences of improvement actions: a qualitative analysis of systems' structure and behavior. Syst. Res. Behav. Sci.

Laurenti, R., Sinha, R., Singh, J., Frostell, B., 2015c. Some pervasive challenges to sustainability by design of electronic products - a conceptual discussion. J. Clean. Prod. 108, 281-288.
Leonard, A., Conrad, A., 2011. The Story of Stuff: The Impact of Overconsumption on the Planet. Our Communities, and Our Health-and how We Can Make it Better. Free Press.

Liao, C.-S., Chuang, H.-K., 2013. Green product innovation: integrating environmental aspects into electrical and electronic equipment development. Manage. Sci. 47 (2), 250-263.

Meskers, C., Hagelüken, C., 2009. Closed loop WEEE recycling? Challenges and opportunities for a global recycling society. In: Proceedings of the 2009 EPD Congress.

Navazo, J.M.V., Méndez, G.V., Peiró, L.T., 2014. Material flow analysis and energy requirements of mobile phone material recovery processes. Int. J. Life Cycle Assess. 19, 567-579.

Neira, J., 2006. End-of-life Management of Cell Phones in the United States. (M.Sc. thesis at Environmental Science and Management for the Donald Bren School of Environmental Science and Management) University of California Santa Barbara.

Nguyen, N.C., Bosch, O.J., Ong, F.Y., Seah, J.S., Succu, A., Nguyen, T.V., Banson, K.E., 2015. A systemic approach to understand smartphone usage in Singapore. Syst. Res. Behav. Sci.

Ongondo, F., Williams, I., Dietrich, J., Carroll, C., 2013. ICT reuse in socio-economic enterprises. Waste Manage., http://dx.doi.org/10.1016/j.wasman.2013.08.020.

OptTek Systems, 2015. Optquest, Available at: http://www.opttek.com/OptQuest (accessed 11.01.15).

Panambunan-Ferse, M., Breiter, A., 2013. Assessing the side-effects of ICT development: e-waste production and management: a case study about cell phone end-of-life in Manado, Indonesia. Technol. Soc., http://dx.doi.org/10. 1016/j.techsoc.2013.04.002.

Peng, W.J., Su, D.Z., 2014. Development of an Online System for Recycling Consumer Electronic Products Using the Internet, NFC and RFID Technologies. Key Eng. Mater. 572, 90-99.

Perthmint, 2013. Precious Metal Prices (online), available at: http://www. perthmint.com.au/investment_invest_in_gold_precious_metal_prices.aspx (accessed 25.07.13).

Phonebloks, 2013. Phonebloks: A Phone Worth Keeping (online), available at: https://phonebloks.com (accessed 08.11.13).

Preston, F., 2012. A Global Redesign? Shaping the Circular Economy. Energy, Environment and Resource Governance. Chatham House, London (online), available at: http://www.chathamhouse.org/publications/papers/view/182376 (accessed 05.04.15).

Rahmandad, H., Sterman, J.D., 2012. Reporting guidelines for simulation-based research in social sciences. Syst. Dyn. Rev. 28 (4), 396-411.

Rashid, A., Asif, F., Krajnik, P., Nicolescu, C.M., 2013. Resource conservative manufacturing: an essential change in business and technology paradigm for sustainable manufacturing. J. Clean. Prod. 57, 166-177.

Ravetz, J., 2000. Integrated assessment for sustainability appraisal in cities and regions. Environ. Impact Assess. Rev. 20 (1), 31-64.

Shokohyar, S., Mansour, S., Karimi, B., 2012. A model for integrating services and product EOL management in sustainable product service system (S-PSS). J. Intell. Manuf., 1-14.

Shokohyar, S., Mansour, S., Karimi, B., 2013. Simulation-based optimization of ecological leasing: a step toward extended producer responsibility (EPR). Int. J. Adv. Manuf. Technol., 1-11.

Silveira, G.T., Chang, S.-Y., 2010. Cell phone recycling experiences in the united states and potential recycling options in brazil. Waste Manage. 30 (11), 2278-2291

Spengler, T., Schröter, M., 2003. Strategic management of spare parts in closed-loop supply chains - a system dynamics approach. Interfaces 33 (6), 7-17.

Sterman, J., 2000. Business Dynamics: Systems Thinking and Modeling for a Complex World. Irwin-McGraw-Hill, ISBN:978-0-07-231135-8.

Takeback-Coalition, 2013. Responsible recycling vs global dumping (online), available at: http://www.electronicstakeback.com/global-e-waste-dumping/ (accessed 15.12.13).

Tischner, U., 2012. Sustainable electronic product design. In: Goodship, V., Stevels, A. (Eds.), Waste Electrical and Electronic Equipment (WEEE) Handbook. No. 30 in Woodhead Publishing Series in Electronic and Optical Materials. Woodhead Publishing Ltd., pp. 404-441, Ch. 19.

Umair, S., Björklund, A., Petersen, E.E., 2013. Social life cycle inventory and impact assessment of informal recycling of electronic ICT, waste in Pakistan. In: Hilty, L., Aebischer, E., Andersson, G., Lohmann, W. (Eds.), Proceedings of the First International Conference on Information and Communication Technologies for Sustainability. ETH, Zurich, pp. 52-58.

UN, 2013. World Population Prospects: The 2012 Revision. United Nations, Department of Economic and Social Affairs (online), available at: http://esa.un. org/unpd/wpp/Excel-Data/population.htm (accessed 04.08.13).

Wang, F., Huisman, J., Stevels, A., Baldé, C.P., 2013. Enhancing e-waste estimates: improving data quality by multivariate input-output analysis. Waste Manage., http://dx.doi.org/10.1016/j.wasman.2013.07.005.

Widmer, R., Oswald-Krapf, H., Sinha-Khetriwal, D., Schnellmann, M., Böni, H., 2005. Global perspectives on e-waste. Environ. Impact Assess. Rev. 25 (5), 436-458.

Wilhelm, W., Yankov, A., Magee, P., 2011. Mobile phone consumption behavior and the need for sustainability innovations. J. Strateg. Innov. Sustain. 7 (2), 20-40.

Williams, E., Kahhat, R., Bengtsson, M., Hayashi, S., Hotta, Y., Totoki, Y., 2013. Linking informal and formal electronics recycling via an interface organization. Challenges 4 (2), 136-153. 